\title{
A psicologia na escola, uma ação de saúde mental para o corpo docente: uma revisão bibliográfica
}

\author{
School psychology, a mental health action for the faculty: a bibliographic review \\ Psicología escolar, una acción de salud mental para el profesorado: una revisión \\ bibliográfica
}

Caroline Fardin Araujo ${ }^{1 *}$, Liana Regina Lima Silva1, Naiara Henrique Lima Faro1, Evan Pereira Barreto1, Aline Batista Pacheco Reis', Valdete Leonídio Pereira1, Vânia Rocha Jordão', Sandra Ferreira Paz¹, Edna Maria de Oliveira Honório', Sandra Pacheco Benevides¹.

\section{RESUMO}

Objetivo: Objetiva-se nesta revisão, apurar o que a literatura trás com relação a necessidade de incluir no corpo escolar profissionais e políticas de psicologia, com a intenção de preservar a saúde mental do professor. Revisão Bibliográfica: Trata-se de uma pesquisa embasada na realidade educacional brasileira, e como o ambiente escolar pode ser nocivo para o corpo profissional quando não está bem estruturado. Implementar políticas de saúde na escola são necessidades reais, posto isto, analisar os campos e concentrar esforços de maneira a não desperdiçar tempo e recursos, para obter uma resposta através dessa proposta. A psicologia, cada dia que passa é mais necessária em todos os campos de convívio social, nas últimas década admitiuse a necessidade dos estudos da área mental para aprimorar e sustentar os bons relacionamentos, além de conservar a saúde mental dos atores sociais. Considerações Finais: O estudo concentra-se na necessidade de intervir de maneira direta nas escolas da educação básica brasileira, introduzindo novos profissionais da psicologia a fim de assegurar a saúde dos profissionais professores.

Palavras-chave: Saúde mental, Saúde, Saúde docente.

\begin{abstract}
Objective: The objective of this review is to ascertain what the literature brings with regard to the need to include psychology professionals and policies in the school staff, with the intention of preserving the teacher's mental health. Bibliographic Review: This is a research based on the Brazilian educational reality, and how the school environment can be harmful to the professional body when it is not well structured. Implementing health policies at school are real needs, that is, analyzing the fields and concentrating efforts so as not to waste time and resources, to get an answer through this proposal. Psychology, every day that passes is more necessary in all fields of social interaction, in the last decade the need for studies in the mental field has been admitted to improve and sustain good relationships, in addition to preserving the mental health of social actors. Final Considerations: The study focuses on the need to intervene directly in Brazilian basic education schools, introducing new professionals in psychology in order to ensure the health of professional teachers.
\end{abstract}

Keywords: Mental health, Health, Teaching health.

${ }^{1}$ Faculdade Vale do Cricaré (FVC), São Mateus - ES. *E-mail: carolinefardin1994@gmail.com SUBMETIDO EM: 7/2020 ACEITO EM: 8/2020 PUBLICADO EM: 10/2020 


\section{RESUMEN}

Objetivo: El objetivo de esta revisión es determinar qué aporta la literatura con respecto a la necesidad de incluir profesionales y políticas de psicología en el personal de la escuela, con la intención de preservar la salud mental del maestro. Revisión bibliográfica: Esta es una investigación basada en la realidad educativa brasileña, y cómo el ambiente escolar puede ser perjudicial para el cuerpo profesional cuando no está bien estructurado. La implementación de políticas de salud en la escuela son necesidades reales, es decir, analizar los campos y concentrar los esfuerzos para no perder tiempo y recursos, para obtener una respuesta a través de esta propuesta. Psicología, cada día que pasa es más necesario en todos los campos de interacción social, en la última década se admitió la necesidad de estudios en el campo mental para mejorar y mantener buenas relaciones, además de preservar la salud mental de los actores sociales. Consideraciones finales: El estudio se centra en la necesidad de intervenir directamente en las escuelas de educación básica brasileñas, presentando nuevos profesionales en psicología para garantizar la salud de los docentes profesionales.

Palabras clave: Salud mental, Salud, Enseñanza de la salud.

\section{INTRODUÇÃO}

A psicologia é o estudo científico do comportamento e da mente humana. Seus campos de estudos envolvem toda a estrutura social e como a mente exerce poder sobre os comportamentos e ações dos seres humanos. Os ambientes de convívio social estão dentro do campo de estudo da psicologia, já que ambos abrigam todos os tipos de convivência e seres humanos. Cabe analisar, através da ciência da mente, quais as possibilidades e responsabilidades exercem os núcleos de desenvolvimento da sociedade, e quando a intervenção é necessária para que os ciclos sejam concluídos, ou para que sejam objeto de estudo, apenas. A psicologia não somente se delimita aos estudos dos agrupamentos sociais, mas também dos atores desses grupos e seus comportamentos individuais (JESUS JG, 2013).

Quando um agrupamento social apresenta variantes, este é o momento que a ciência comportamental entra em campo. Analisar as possibilidades e desconstruir conceitos errados, funciona como exercício social para desenvolver qualquer ambiente doente. A ideia de desenvolvimento nasce com o melhoramento e 0 progresso, que conduzirá a sociedade para que os direitos individuais e os prazeres humanos sejam respeitados e não objeto de exclusão. A psicologia está presente em todos os momentos da vida, desde ao acordar e coçar a cabeça, até nos sonhos quando expomos a nós mesmos desejos e realidades ocultas no nosso subconsciente (MANDELBAUM B, 2012).

O ambiente escolar é amplamente dotado de objetos de estudos da psicologia. No ambiente escolar é possível observar como as futuras gerações reagem ao convívio social, e como elas se adaptam as individualidades humanas. A ideia sociointeracionista de Vygotsky aponta para os círculos sociais que a criança está e a responsabilidades sobre o seu desenvolvimento. Já os responsáveis pelas influências exercidas sobre as futuras gerações, também se apresentam como potenciais objetos de estudo com seus comportamentos e necessidades. É de extrema importância averiguar a participação social e as contribuições dos professores nos ambientes de ensino, e classifica-los como classe de extrema importância para 0 desenvolvimento social dos alunos, e preservar sua saúde mental como forma de garantir uma transmissão de conhecimento segura (DIEHL L e MARIN AH, 2016).

As pressões exercidas sobre o corpo docente das escolas públicas brasileiras variam de inúmeras formas. Desde a parte que o professor adentra a sala de aula para ensinar inúmeros alunos diferentes e que absorvem de forma diferente o conhecimento, até o momento que ele conclui suas atividades diárias e precisa retornar as atividades comuns do cotidiano do trabalhador. A carga horária de um professor, que costumeiramente é chamada de cadeira, varia de 30 a 35 horas semanais. A grande maioria dos professores brasileiros possuem duas cadeiras, o que varia de 60 a 70 horas semanais de trabalho. $O$ tempo de desenvolver atividades, corrigir provas e elaborar o plano a ser apresentado, geralmente estão excluídos das horas semanais trabalhadas, 0 que pode interromper ciclos essenciais dos professores, como o convívio familiar e a prática de atividades que geram prazer (ALMEIDA JLV e GRUBISICH TM, 2011). 
A necessidade de introduzir a psicologia nas escolas é real, não somente para lidar com o comportamento dos alunos, mas também para conhecer e introduzir políticas públicas de prevenção do adoecimento mental dos professores. Seus comportamentos e práticas precisam ser averiguados a fim de aprimorar as didáticas e inovar nas formas de transmitir o conhecimento, formas essas de alta importância quando tratamos das individualidades no ambiente da sala de aula e como elas podem ser contempladas. O professor também possui sua individualidade e requer cuidados, principalmente no modelo educacional brasileiro que não atende as necessidades reais na magistratura e por isso acaba prejudicando todo o conjunto. Os reais motivos giram em torno da não destinação de recursos suficientes para o desenvolvimento de pesquisas e atendimento das necessidades físicas e materiais (AUGUSTO MH, 2015).

Objetiva-se nesta pesquisa revisional propor a reunião dos materiais existentes na área da saúde mental, psicologia e educação, todos em consenso, para apresentar resultados importantes e de grande valia para aprimoramento do ambiente escolar. O foco é a saúde do professor e como ela é importante para um ambiente educacional saudável e próspero nas didáticas utilizadas. A psicologia, por sua vez, aparece como alternativa as escolas da educação básica brasileira, e os estudos do comportamento humano são os instrumentos para averiguar as propostas ideias e as atividades necessárias para garantir que os profissionais docentes não sejam expostos a risco no exercício da sua profissão.

\section{REVISÃO BIBLIOGRÁFICA}

A saúde do trabalhador, durante muitos séculos, foi tratada com desprezo e de forma secundária. O lucro sempre importou mais, tanto pela grande demanda de desempregados, quanto pela ausência de movimentos trabalhistas e de direitos conquistas. A primeira grande reunião social que buscou consagrar os direitos do cidadão, que obteve êxito, foi a revolução francesa, que explodiu no ano de 1789, e que exerce influência até os dias atuais nas lutas de classe e nas bandeiras sociais contra a opressão do Estado e dos mais ricos. Entretanto, em nome do lucro e debruçado na influência das altas classes, os detentores de poder financeiro ainda encontram maneiras de manipular a classe trabalhadora ou cercear seus direitos quando isso movimenta seus interesses (POCHMANN M, 2018).

Das classes trabalhadoras mais robustas no Planeta, a maior delas é a dos profissionais da educação, mais exatamente a dos professores. Isso se deve a importância que o mundo moderno tem dado ao desenvolvimento cientifico e tecnológico. Globalizar a educação e garantir o acesso democrático as escolas tem sido a maneira mais eficaz de selecionar grandes mentes e fortalecer o desenvolvimento e o progresso. Muito se perdeu de pessoas capazes, com a falta da igualdade de oportunidades, já que as escolas e universidades, historicamente foram locais extremamente elitizados. Entretanto, a garantia de que novos professores conseguirão expressar da melhor maneira a didática proposta e assim permitir que o corpo discente ascenda às ciências para melhorar a qualidade de vida humana, é uma questão de condições dignas de trabalho (GOMES VAFM, et al., 2019).

As condições mínimas que o docente necessita para dar segmento a transmissão do conhecimento é uma estrutura física e a remuneração para que o seu tempo não se torne um empecilho. Entretanto, outras questões pertinentes influenciam diretamente na qualidade e na manutenção das escolas, principalmente no Brasil, que caminha vagarosamente no desenvolvimento de um método mais eficaz e eficiente, que contemple as diferenças e respeite as individualidades. Das questões necessárias a se tratar para preservar a qualidade do ensino através dos cuidados com o professor, a saúde mental é um cuidado necessário e que já deveria ter muitas políticas públicas introduzidas com esta finalidade. Não somente ações profissionais, mas políticas remuneratórias, que exercem garantias necessárias ao programa educacional, já que é a forma de atender as necessidades pessoais e transmitir segurança aos professores (OLIVEIRA HLG e LEIRO ACR, 2019).

Mas como trabalhar a saúde mental do professor, e como averiguar quais métodos devem ser adotados para que sejam contemplados da maneira correta? As políticas de saúde necessitam de profissionais específicos de cada área para serem desenvolvidas, por isso, trabalhar questões de saúde mental perpassa antes por questões comportamentais e análises apuradas das atividades humanas. Antes de tudo, há que se considerar que o professor é um ser humano com necessidades biológicas como as de qualquer outro profissional, e por isso requer cuidados e tempo para receber os cuidados necessários. 
Mas como a rotina do professor, principalmente devido as extensas cargas horárias, é extremamente sobrecarregada, há que se pensar uma forma de reduzir o tamanho de tal jornada sem prejuízos financeiros ao profissional e como incluir um profissional específico para análise comportamental no ambiente de trabalho (COUTINHO AFJ, et al., 2015).

Muitas políticas recentes que buscam inserir a psicologia na escola foram tratadas com real importância e foram inclusive objeto de leis propostas no Congresso Nacional. A intenção não é somente garantir que 0 comportamento e as necessidades dos alunos sejam atendidas, mas também promover aos professores um campo de desaceleração e reflexão, o que colabora diretamente para a continuidade do com convívio e do bom desenvolvimento dos métodos de transmissão de conhecimento.

Existem vários campos específicos que fornecem o cerne dos problemas e facilitam a resolução dos conflitos, e para identificar e tratar tais demandas, as inserções precisam ser certeiras a fim de não manter ou agravar ainda mais os problemas. A única maneira de reservar com responsabilidade tais práticas, é buscando aqueles que de fato estão aptos a lidar com essas situações, os psicólogos (PETRONI AP e SOUZA VLT, 2017).

\section{O Direito ao psicólogo na escola}

As conquistas de direitos, desde os séculos passados, foram se aprimorando até chegar no campo das ideias e das proposições. No passado, direitos sociais eram conquistados apenas através de revoluções e lutas sangrentas. Quando as classes trabalhadoras entenderam que sem elas nada seria produzido, aprenderam a exigir seus direitos e conquistar espaços.

Nos tempos atuais, existem inúmeras formas de conquistar direitos, e ambas as formas são garantidas e positivadas em lei, para preservar o que diz o artigo $3^{\circ}$ da Constituição Federal, que o Brasil será um País inclinado a combater as desigualdades sociais. De tal forma, na linha histórica dos movimentos trabalhistas, direitos como melhores condições de trabalho, remunerações justas, carga horária humanizada e o décimo terceiro salário, foram conquistados na base da insistência e da conscientização (PESSANHA EGF e ARTUR K, 2013).

Recentes conquistas para a área da educação percorreram um imenso caminho até serem implementadas de fato. A recente abertura das portas dos colégios para os filhos de pessoas das classes mais baixas, só foi efetivada de fato quando essas famílias foram incluídas em programas assistenciais, que permitiam que os membros mais novos da família fossem a escola, se alimentassem ao menos três vezes ao dia e não precisassem trabalhar período integral para complementar a renda familiar.

Não somente em benefício dos alunos e das suas famílias, mas a criação de créditos estudantis, a ampliação do número de vagas nas universidades federais e os programas de financiamento, todos aliados ao aumento do número de instituições Federais, forneceram um número maior de profissionais da educação, o que colaborou para reduzir as cargas exaustivas de professores, com novos profissionais a disposição (SILVEIRA AAD, 2010).

A chegada dos psicólogos nos ambientes educacionais, forneceu o fortalecimento de mais direitos básicos garantidos na Constituição de 1988, a garantia do direito à saúde e a educação foram amplamente subsidiados pela nova política. Os ambientes escolares se tornaram altamente hostis e descontrolados, já que com o aumento da demanda, aumentou-se também os conflitos ocasionados pelas diferenças (ARREGUY ME, 2014).

Muitas escolas se anteciparam e com base em projetos estaduais e municipais, implementaram políticas de saúde nas escolas, incluindo a presença do profissional da psicologia. Mas a lei de fato foi apresentada no ano de 2011 pelo Senado José Guimarães, entretendo foi arquivada e colocada novamente em votação no ano de 2019, mesmo ano em que foi promulgada após veto presidencial sob o número 13.935/2019 (AGÊNCIA SENADO, 2019). A lei dispõe sobre a prestação de serviços de psicologia e de serviço social nas redes públicas de educação básica. 
Art. $1^{\circ}$ As redes públicas de educação básica contarão com serviços de psicologia e de serviço social para atender às necessidades e prioridades definidas pelas políticas de educação, por meio de equipes multiprofissionais. $\S 1^{\circ}$ As equipes multiprofissionais deverão desenvolver ações para a melhoria da qualidade do processo de ensino-aprendizagem, com a participação da comunidade escolar, atuando na mediação das relações sociais e institucionais. $\S 2^{\circ} \mathrm{O}$ trabalho da equipe multiprofissional deverá considerar o projeto político-pedagógico das redes públicas de educação básica e dos seus estabelecimentos de ensino. Art. $2^{\circ}$ Os sistemas de ensino disporão de 1 (um) ano, a partir da data de publicação desta Lei, para tomar as providências necessárias ao cumprimento de suas disposições (BRASIL, 2019).

Existem outros programas que contemplam a saúde na escola através de legislações complementares. $O$ Programa Saúde na Escola (PSE) foi aprimorado no ano de 2017 através da portaria 1.055. A portaria teve como objetivo simplificar e ampliar políticas de saúde no ambiente escolar. Entretanto, não contemplou a área da saúde mental, inserindo profissionais da psicologia, e também não atentava para as questões sociais e a sensibilidade da ocasião, que pede profissionais da área das ciências sociais.

O Brasil além de ter fortalecido sua demanda desses profissionais, com a ampliação do número de brasileiros nas universidades, também se aprimorou em pesquisa e conhecimento, isso dado ao aumento do número de recursos para pesquisas e ao progresso pedagógico alcançado no mundo todo (ATALIBA $P$ e MOURÃO L, 2018).

Todas essas políticas públicas no ambiente escolar afetam positivamente e diretamente nas questões de saúde mental do professor. Com a compreensão dos comportamentos e transtornos ocasionados no ambiente de estudo, os professores terão esclarecimentos e oportunidades maiores de clarificar a transmissão das didáticas e até participar melhor dos seus processos de formação. A ação indireta de construir pontes entre saúde e educação, para o professor, é um caminho de largas conquistas, até porque, o enorme índice de violência, seja ela física ou psicológica, de alunos para com professores, nasce da ausência da compreensão dos transtornos sociais que são dispensados ao aluno, e consequentemente os docentes acabam servindo de "esponjas" que absorvem todas as toxidades dessas relações indesejadas. É indispensável, para assegurar o direito a um ambiente de trabalho saudável para os profissionais da educação, inserir políticas de saúde no ambiente escolar (DOS SANTOS JV e GONÇALVES CM, 2016).

\section{Os benefícios de profissionais da psicologia nas escolas para a saúde dos docentes}

As ações de saúde no ambiente escolar apresentam resultados positivos de inúmeras formas, até mesmo em áreas e setores que não são objeto da política, os resultados costumam se apresentar. Quando os profissionais do programa PSE foram inseridos no ambiente escolar para diagnosticar doenças comuns em crianças e adolescentes, além de promoverem campanhas de conscientização e informações indispensáveis para um crescimento saudável, as famílias foram atingidas, gerando um resultado social muito mais amplo do que se esperava. Os alunos obtiveram conhecimentos que seus lares ainda não tinham tido acesso, e foram sendo distribuídos de filhos para pais, invertendo o que a sociedade tratava com normalidade, onde os pais é que ensinavam seus filhos (FIGUEIREDO TAM, et al., 2010).

Quando a saúde do aluno é colocada como objeto de estudo e tratamento, é possível identificar os resultados através da produtividade e da reação dos discentes no ambiente escolar. Quando as políticas acertam em seus objetivos e conseguem produzir resultados satisfatório, é possível notar que todo o conjunto presente recebe benefícios. Os alunos conseguem absorver melhor os conhecimentos, o professor consegue aproveitar melhor o tempo e aplicar técnicas mais efetivas, além da equipe pedagógica que consegue ampliar o leque de possibilidades apostando no comportamento dos alunos e conhecendo o ambiente que estará trabalhando. Os estímulos causados por um ambiente promissor ao trabalho são facilmente notados, basta saber que a inteiração de professor e aluno depende da sensibilidade das duas partes e dos agentes que trabalham ocultos para a promoção da educação (MATTOS AR, et al., 2013). 
A promoção do ser humano é necessária em para obter desenvolvimento e manter a roda do progresso. O ser humano necessita de estímulos e ser tratado com dignidade para dar continuidade ao desenvolvimento saudável das suas atividades. Considerar que importa para o docente que sua saúde mental é um objeto de investimento e de políticas públicas, é como promover o encontro do ser humano com a humanidade, é valorizar uma classe que por ora foi desprezada e descaracterizada, tanto pelo aumento da quantidade de servidores tanto pelo histórico do machismo estrutural que elencou a mulher como professora das séries iniciais, e por isso menos importante na classe trabalhadora. A realidade está sempre em modificação, e atentar-se as reações que advém dessas mudanças, é um estudo clínico e minucioso do comportamento, pois existem reações que são ocultas aos olhos leigos, que podem justificar ações indesejadas (SILVA AM e DA SILVA SMC, 2019).

Um dos adoecimentos mentais mais identificados em professores é a síndrome de Bornout, ou Síndrome do Esgotamento Profissional. Trata-se de um distúrbio intimamente ligado ao esgotamento profissional, cansaço extremo que são decorrentes de jornadas exaustivas e danosas. $\mathrm{O}$ excesso de trabalho que é a principal causa do desenvolvimento desse distúrbio, não está apenas ligado a trabalhos que envolvem força física, mas é comprovado através dos estudos da mente que o desgaste emocional e mental causa inúmeros danos no corpo físico. A teoria funcionalista dos valores humanos contribuiu para pesquisas no campo da organização, como comprometimento organizacional, bem-estar emocional, fadiga e esgotamento (SOUZA S, et al., 2016).

Embora esse não seja um pré-requisito para trabalhar na área, atualmente, os psicólogos podem obter o título realizando o exame realizado pela Comissão Federal de Psicologia ou obter reconhecimento de especialistas no campo da psicologia escolar / educacional, mantendo o reconhecimento do conselho acima. Para se qualificar para o teste, os profissionais devem fornecer alguns critérios exigidos pelo Conselho Federal de Psicologia (CFP), como registrar-se no comitê regional de psicologia por pelo menos dois anos e certificar a prática profissional nas escolas e na educação por pelo menos dois anos. Outro aspecto importante que parece ter alcançado consenso em pesquisas nesse campo é que, no processo educacional, os psicólogos escolares devem não apenas se engajar no trabalho de cura ou patologia, mas também devem se concentrar na prevenção e promover o desenvolvimento de atores para participar do processo educacional. , Tendo em conta o potencial de diferentes participantes na formação educacional (SOUZA S, et al., 2016).

\section{CONSIDERAÇÕES FINAIS}

Conclui-se que a saúde mental do docente, a fim de ser preservada, perpassa por inúmeros campos e necessidades. Desde a remuneração digna, aos direitos e garantias a saúde com os psicólogos escolares, até estruturas físicas adequadas que permitam um melhor exercício da atividade do educador e não transformem a sala de aula em um local de tortura, sem condições laborais e estressante. A fim prevenir adoecimentos, a maneira mais eficaz é buscar a compreensão dos problemas, identificar os pontos com o auxílio de profissionais especialistas, e introduzir políticas públicas remuneratórias, educacionais e que atinjam a saúde pública de igual modo.

\section{REFERÊNCIAS}

1. AGÊNCIA SENADO. 2019. In: SENADO NOTÍCIAS, promulgada lei que garante atendimento de psicólogo a alunos de escolas públicas. Brasília: site do senado federal. Disponível em: https://www12.senado.leg.br/noticias/materias/2019/12/12/promulgada-lei-que-garante-atendimento-de-psicologo-aalunos-de-escolas-publicas. Acesso em: 3 jun. 2020.

2. ALMEIDA JLV, GRUBISICH TM. O ensino e a aprendizagem na sala de aula numa perspectiva dialética. Revista Lusófona de Educação, 2011; 17(3): 65-74.

3. ARREGUY ME. Violência e ausênciade psicólogos nas escolas. Physis, Revista de Saúde Coletiva, 2014; 24(1): 229252.

4. ATALIBA P, MOURÃO L. Avaliação de impacto do Programa Saúde nas Escolas. Psicologia Escolar e Educacional, 2018; 22(1): 27-35.

5. AUGUSTO MH. A valorização dos professores da educação básica e as políticas de responsabilização: o que há de novo no plano nacional de educação?. Cad. Cedes, 2015; 35(97): 535-552. 
6. BRASIL. 2019. In: CONGRESSO NACIONAL, dispõe sobre a prestação de serviços de psicologia e de serviço social nas redes públicas de educação básica. Brasília: site oficial da casa civil, Presidência da República. Disponível em: http://www.in.gov.br/web/dou/-/lei-n-13.935-de-11-de-dezembro-de-2019-

232942408? inheritRedirect=true\&redirect=\%2Fweb\%2Fguest\%2Fsearch\%3FqSearch\%3DLei\%252013.935\%25202 019. Acesso em: 3 jun. 2020.

7. COUTINHO AFJ, et al. A psicologia na escola - (re)pensando as práticas pedagógicas. Psicologia da Educação, 2015; 40(3): 103-114.

8. DIAS ACG, et al. Psicologia Escolar e possibilidades na atuação do psicólogo: Algumas reflexões. Revista Quadrimestral da Associação Brasileira de Psicologia Escolar e Educacional, 2014; 18(1): 105-111.

9. DIEHL L, MARIN AH. Adoecimento mental em professores brasileiros: revisão sistemática da literatura. Estudos Interdisciplinares em Psicologia, 2016; 7(2): 64-85.

10. DOS SANTOS JV e GONÇALVES CM. Psicologia educacional: Importância do psicólogo na escola, 2016. O Portal dos Psicólogos, 2016: 1-22.

11. FIGUEIREDO TAM, et al. A saúde na escola: um breve resgate histórico. Ciência \& Saúde Coletiva, 2010; 15(2): 397407.

12. GOMES VAFM, et al.Condições de trabalho e valorização docente: um diálogo com professoras do ensino fundamental. Revista Brasileira de Estudos Pedagógicos, 2019; 100(225): 277-296.

13. JESUS JG. Psicologia das massas: Contexto e desafios brasileiros. Psicologia \& Sociedade, 2013; 25(3): 493-503.

14. MANDELBAUM B. Sobre o campo da Psicologia Social. Psicologia USP, 2012; 23(1): 15-43.

15. MATTOS AR, et al. O cuidado na relação professor-aluno e sua potencialidade política. Estudos de Psicologia, 2013; 18(2): 369-377.

16. OLIVEIRA HLG, LEIRO ACR. Políticas de formação de professores no Brasil: referenciais legais em foco. ProPosições, 2019; 30(1): 1-13.

17. PESSANHA EGF, ARTUR K. Direitos trabalhistas e organização dos trabalhadoresnum contexto de mudanças no mundo do trabalho:efeitos sobre os trabalhadores da saúde. Ciência \& Saúde Coletiva, 2013; 18(6): 1569-1580.

18. PETRONI AP, SOUZA VLT. Psicologia Escolar: análise sobre dificuldades e superações no Brasil e Portugal. Psicologia Escolar e Educacional, 2017; 21(1): 13-20.

19. POCHMANN M. Desestabilização do trabalho. Saúde Debate, 2018; 42(3): 67-77.

20. SILVA AM, DA SILVA SMC. Psicologia Escolar na Assistência Estudantil: estudo de caso no Cefet - MG Araxá. Psicologia Escolar e Educacional, 2019; 23(1): 1-13.

21. SILVEIRA AAD. A busca pela efetividade do direito à educação: análise da atuação de uma Promotoria de Justiça da Infância e Juventude do interior paulista. Educar em Revista, 2010; 1(2): 233-250.

22. SOUZA S, et al. Síndrome de burnout e valores humanos em professores da rede pública estadual da cidade de João Pessoa: Um estudo correlacional. Análise Psicológica, 2016; 34(2): 119-131. 